attempt to replicate. Science, $1965,150$. 1749.

HARTY, A. L., KEITH-LEE, P., \& MORTON, w. D. Planaria: Memory transfer through cannabalism re-examined. Science, 1964, 146, 274-275.

HOFFMANN, R. $\vdash$., STEWART, C. N., \& BHAGORAN, H. M. Failure to transfer a learned response in rats using a brain extract containing RNA. Psychonomic Science, 1967, 9, 151-152.

JACOBSON, A. L., BABICH, F. R., BUBASH, S., \& JACOBSON, A. Differential approach tendencies produced by injection of RNA from trained rats. Science, 1965, 150, 636 .

LUTTGES, M., et al. An examination of "transfer of learning" by nucleic acid. Science, $1966,151,834-837$.
UNGAR, G., GELSON, L., \& CLARK, R. H. Chemical transfer of learned fear. Nature, $1968,217,1259-1261$.

WALKER, D. R. Memory transfer in planarians: An artifact of the experimental variables. Psychonomic Science, 1966, 5, 357-358.

WALKER, D. R., \& MILTON, G. A. Memory transfer vs. sensitization in cannibal planarians. Psychonomic Science, 1966, 5, 293-294.

\section{NOTES}

1. The authors wish to express their appreciation for the invaluable assistance of Mrs. June Blackwell in the surgical and brain-extract procedures.

2. Ungar, G. Personal communication, 1968.

\title{
Cerebral lesions and the excretory alkali metal response (EAMR) in reptile ${ }^{1}$
}

IRWIN M. SPIGEL, ${ }^{2}$ ALEX RAMSAY, and JO-AN SEGGIE, University of Toronto, Toronto 5, Canada

Unlike the climbing-response decrement observed in cerebrally lesioned turtles, and which was independent of contingent shock, lesioned and sham-operated Ss alike produced elevated urinary $\mathrm{Na}^{+}$and $\mathrm{K}^{+}$ levels when under periodic shock. Some consistency with earlier behavioral observations was evident in the significantly lower cation concentrations of shocked lesioned Ss for the first 2 days of the experiment.

Cerebral lesions in the painted turtle, Chrysemys picta marginata, have been observed to impair the ubiquitous climbing response of confined Ss (Spigel \& Ellis, 1966). The climbing decrement was evident whether or not such behavior resulted in a contingent electric shock. A virtually identical climbing deficit, independent of consequent shock, was also shown to follow intraperitoneal injection of d-amphetamine (Spigel \& Ellis, 1967). The production of a similar deficit following either cerebral insult or the administration of a sympathomimetic agent presumed to act on lower brain structures suggested that the reptilian cerebrum and lower centers may be somewhat antagonistic in nature. The data were also viewed as supporting the speculation of Goldby \& Gamble (1957) that parts of the reptilian hemispheres may be of significance in the orientation of this species to its environment and in the participation of this tissue in emotionally integrative behavior patterns.
More recently, Spigel \& Ramsay (1969) have shown that total alkali metal (combined sodium and potassium) excretion in the turtle is a consistent index of stress. This excretory alkali metal response (EAMR) was not only greater in turtles administered periodic electric shock, but persisted after shock termination when Ss were retained in the surround associated with the antecedent noxious stimulation.

Consideration of these observations led to the question of whether cerebral lesions might not affect the EAMR in a manner consistent with the decremental climbing behavior that was shown to follow such treatment.

\section{SUBJECTS}

Forty male central painted turtles (Chrysemys picta marginata), 4 to 5 years of age as estimated from carapace length, were employed. All had been maintained in a colonial Wahmann tank for at least 3 weeks prior to the experiment.

\section{APPARATUS}

An IL flame photometer was used for $\mathrm{Na}^{+}$and $\mathrm{K}^{+}$determinations. Four white plastic food-preserving boxes ( $8 \times 4 \times 4$ in.) with tightly fitted lids, perforated with four small holes to permit air to enter, housed Ss during the experimental treatment period. A timer, connected to a variable-shock generator, was set to deliver a $1.5-\mathrm{V}$ shock of $3-\mathrm{sec}$ duration every $57 \mathrm{sec}$ for $12 \mathrm{~h}$ each day to $\mathrm{Ss}$ in groups so designated. The current was administered to Ss by means of insulated alligator clips inserted through holes in the boxes and connected to the tail and right hindleg. The timer was automatically reset by a gear-activated switch.

\section{PROCEDURE}

The Ss were assigned randomly to one of four conditions: cerebrally lesioned and shocked, sham-operated and shocked, cerebrally lesioned and nonshocked, and sham-operated and nonshocked. One $S$ in each of the lesioned-shocked and sham-operated, nonshocked groups died, and the data were discarded. Twenty-four hours after surgery, Ss were placed individually in the plastic containers with $25 \mathrm{ml}$ of distilled water, and the electrodes were attached. Although all Ss were fitted with the clips, only those in one of the lesioned and one of the sham-operated groups received the periodic shock. Habitat water was analyzed for $\mathrm{Na}^{+}$and $\mathrm{K}^{+}$on Days 2, 4, and 6 of the 6-day period of the experiment, and the water was replaced on Days 2 and 4. On Day 6, Ss were sacrificed by decapitation, and the heads were stored in $10 \%$ formalin for histological verification of the lesion.

\section{SURGERY}

Heads of Ss were extended and taped in position. Anaesthesia was accomplished by retaining $\mathrm{Ss}$ in crushed ice for $2 \mathrm{~h}$. Lesions were placed medially in the cerebral hemispheres. Holes were bored bilaterally through the skull with a dental drill and the tip of a hyfrecator needle inserted through the apertures to a depth of $2 \mathrm{~mm}$. During a 10 -sec current application, the needle was rotated constantly at an angle of about $60 \mathrm{deg}$ from the ventricle. Ss were retumed to the home tank immediately. Sham lesions followed the same procedure up to, but not including, placement of the needle.

\section{RESULTS}

Total excretory alkali metal remained significantly higher for all shocked Ss over the entire 6-day experimental period. It was only in the analysis of Day 2 residual fluid that shocked cerebrally lesioned turtles revealed a significantly reduced excretion of $\mathrm{Na}^{+}$and $\mathrm{K}^{+}$as compared with

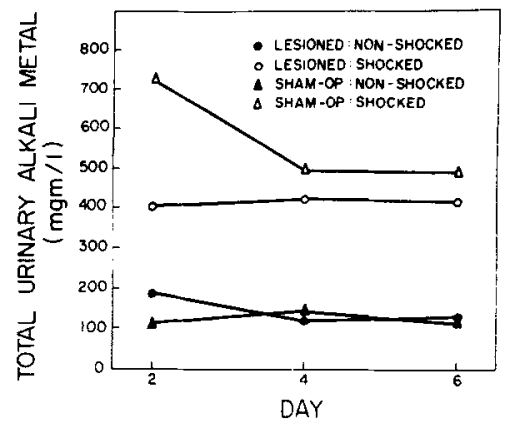

Fig. 1. Concentrations of total excretory alkali metal in the habitat water for the four treatment groups on Days 2, 4, and 6. Values represent means for combined $\mathrm{Na}^{+}$ and $\mathrm{K}^{+}$in milligrams per liter. 
shocked sham-operated Ss. The excretory alkali metal pattern for the 6-day period is shown in Fig. 1.

A Kruskal-Wallis test of the 3-day mean EAM values for $S s$ of all four groups yielded an $\mathrm{H}$ of $25.6 \quad(\mathrm{p}<.001)$. Mann-Whitney $U$ tests of group differences for each analysis day were carried out, the only significant comparison being that between cerebrally lesioned and sham-operated shocked Ss on Day 2 $(\mathrm{U}=19)$.

\section{DISCUSSION}

Previous study has implicated cerebral tissue in the confinement-induced climbing response of the turtle chrysemys. This was taken as support for the involvement of the hemispheres in the emotional integration of this species. The current examination, utilizing the increased excretory alkali metal response as an index of stress in the turtle, revealed only partial consistency with the earlier behavioral findings.

Unlike the climbing-response decrement observed in previous experiments (Spigel \& Ellis, 1966)-a decrement that appeared in all cerebrally lesioned $\mathrm{Ss}$ and was independent of shock contingency-only the shocked turtles, lesioned and sham-operated alike, produced elevated EAM levels as compared with nonshocked controls. Some consistency with earlier observation was evident in the significantly lower EAM concentrations of shocked, lesioned Ss as compared with shocked sham-operates for the first 2 days of the experiment. For the remaining 4 days, the excretory $\mathrm{Na}^{+}$and $\mathrm{K}^{+}$of shocked sham-operates fell to the level of shocked lesioned turtles.

Although a definitive explanation of the apparent discrepancy between the previously observed behavioral deficit and the current excretory cation determinations is not yet possible, some speculation may be offered in the light of inferences drawn from the earlier examination of the EAMR. It had been tentatively suggested (Spigel \& Ramsay, 1969) that a mechanism similar to the renin-angiotension system of mammals may operate in reptiles, whereby stress-induced changes in blood pressure lead to alterations in glomerufiltration rate and aldosterone levels. The subsequently reduced tubular reabsorption of sodium could then yield the higher excretory electrolyte level. Such a mechanism, and its implication of aldosterone whose secretion is independent of ACTH production, would suggest a physiological basis other than that involving the hypophyseal-adrenal axis.

It is also possible, of course, that periodic shock constitutes far more stressful stimulation for chrysemys than confinement, exceeding any limits of control by cerebral tissue alone. It would now appear necessary to determine whether or not confinement alone induces significant changes in excretory alkali metal level.

What must still be accounted for, however, is the initial reduction of excretory $\mathrm{Na}^{+}$and $\mathrm{K}^{+}$observed in the shocked, lesioned Ss which continues to implicate the cerebral hemispheres in some overall emotionally integrative response.

\section{REFERENCES}

GOLDBY, F., \& GAMBLE, H. J. The reptilian cerebral hemispheres. Biological Review, 1957, 32, 383-420.

SPIGEL, I. M., \& ELLIS, K. R. Cerebral lesions and climbing suppression in the turtle. Psychonomic Science, 1966, 5, 211-212.

SPIGEL, I. M., \& ELLIS, K. R. D-amphetamine and climting suppression in the turtle. Psychological Reports, 1967, 20, 1257-1258.

SPIGEL, I. M., \& RAMSAY, A. Excretory electrolytes and response to stress in a reptile. Journal of Comparative \& Physiological Psychology, 1959, 68, 18-21. NOTES

1. This research was supported by a grant from the National Research Council of Canada.

2. Requests for reprints should be sent to Irwin M. Spiget, Department of Psychology, University of Toronto, Toronto 5, Canada. 